\title{
The unfinished child survival revolution: the role of nutrition
}

\author{
Lars Åke Persson
}

International Maternal and Child Health, Department of Women's and Children's Health, Uppsala University, Uppsala, Sweden

Abstract

Since an impressive reduction in child mortality in the 1970s to early 1990s improvements have slowed down, and more than 10 million children die annually under the age of 5 years. Most of these deaths occur in relatively few countries, mainly in South Asia and Africa south of the Sahara. Given the causal links between nutrition and mortality in infancy and childhood it is of great importance to assess the role of nutrition in further improvements in global child survival. This study assessed what proportion of global under-five deaths could be prevented by available and efficacious nutrition interventions, through a review of recent papers of child survival and the role of nutrition in the prevention under-five deaths in a global perspective. It was found that undernutrition is an underlying cause in more than half of global under-five deaths. Most deaths are caused directly by bronchopneumonia, diarrhoeal diseases, diseases of the newborn, malaria, measles and HIV/AIDS. Specific and proven efficacious nutrition interventions could prevent more than onethird of the current 10 million child deaths. The most important nutrition-related interventions are exclusive breast-feeding, zinc supplements for treatment and prevention, complementary feeding, vitamin A supplementation and oral rehydration therapy. The coverage of many of these efficacious interventions is usually low. The potential role of nutrition interventions to promote global child survival is great. Child survival issues and the role of nutrition in preventing child deaths must be reintroduced on international health agendas. This is a prerequisite for reaching the fourth Millennium Development Goal, a reduction in child deaths by two-thirds before 2015 .

Keywords: breast-feeding; complementary feeding; oral rehydration therapy; prevention; under-five mortality; undernutrition; vitamin A; zinc

Received: 3 Oct. 2005; Accepted: 6 Oct. 2005

\section{Introduction}

More than 10 million children a year, or 30000 a day, die from usually treatable or preventable causes (1). In the Millennium Development Goals the world's governments committed themselves to a reduction in child mortality by two-thirds from the 1990 level to 2015 (the fourth Millennium Development Goal). According to a recent review by the United Nations this is possible, but only by sustained efforts to expand known efficacious and low-cost interventions (2).

The region with the highest under-five mortality rates is sub-Saharan Africa, where there has been only a small reduction from the 1990 level to the present (2005) (2). South Asia had a high child death risk in the 1970s and despite a major reduction in mortality risks some 3.5 million of the annual child deaths still occur in this region.
Half of the worldwide child deaths take place in five countries (India, Nigeria, China, Pakistan and DR Congo) and $90 \%$ in 42 countries (3). Progress in reaching the fourth Millennium Development Goal varies between regions, increasing the global inequity in child survival $(2,4)$.

It has been known for several decades that undernutrition and micronutrient deficiencies impair immune defence as well as non-immune host defences and increase the risk of disease and fatal outcome $(5,6)$. Estimates of the global burden of diseases show that the leading specific causes (all ages) are lower respiratory infections, diarrhoeal diseases and perinatal disorders, and that childhood malnutrition is the first and outstanding risk factor for global disease burden, contributing $15.9 \%$ of disability-adjusted life years (DALYs) worldwide (7). Given the epidemiological evidence 
for undernutrition as an underlying cause of child mortality, the important question is the extent to which global child deaths can be prevented by known, efficacious and affordable nutrition interventions.

\section{Methods}

This review is based on recently (2000-2005) published papers that discuss efficacy, effectiveness, coverage and/or prevented fractions of nutrition interventions in children in relation to child mortality. A series of papers on child survival published in the Lancet in 2003 are central to this review, and also provide a broader view on the preventability of child deaths by non-nutritional interventions $(3,4,8)$. Literature searches were performed using the above-mentioned keywords and child mortality. In addition, searches were undertaken for the specific interventions discussed in the paper.

The review briefly presents the current under-five mortality trends in the world, discusses estimates of undernutrition as an underlying cause of child deaths, and discusses the main nutrition interventions that have been proven to be efficacious in the prevention of under-five deaths. Estimates of global mean coverage of these interventions are presented and the potential impact of achieving universal coverage is presented and discussed.

\section{Results}

The pioneering results of the studies of the Institute of Nutrition of Central America and Panama (INCAP) showed that malnutrition and infections are generally synergistic, and provided the basis for an active role of nutrition interventions in the efforts to improve child health and survival in the 1960s and onwards (5). There is no apparent threshold in the association between undernutrition and mortality, and the effect increases exponentially with declining weight for age (9). Although most deaths are directly caused by bronchopneumonia, diarrhoeal diseases, diseases of the newborn, malaria, measles and HIV/AIDS, $53 \%$ of all child deaths have been shown to have undernutrition as an underlying cause. This attributable proportion varies from $45 \%$ for deaths due to measles to $61 \%$ for deaths due to diarrhoeal diseases (10).

Four specific nutrition interventions play a significant role in the prevention of child deaths; breast- feeding, complementary feeding, and supplementation with zinc and vitamin A. Further, the role of oral rehydration therapy (ORT) in treating dehydration and improving recovery and growth after episodes of diarrhoea is outstanding (see Fig. 1).

The World Health Organization recommends exclusive breast-feeding during the first 6 months of life, followed by appropriate complementary feeding and continued breast-feeding (11). The excess risk of death in non-breast-fed infants in impoverished settings is well documented and includes mortality in sepsis, pneumonia and diarrhoea (12). Globally, only just over one-third of infants are exclusively breast-fed up to 6 months, while $90 \%$ continue breast-feeding during the second half of infancy (Table 1). In countries where maternal HIV infection is prevalent there is a potential risk of mother-to-child transmission of HIV during lactation. This has been considered in the estimated potential impact of global coverage of breast-feeding recommendations, but breastfeeding remains the single most important nutrition intervention in the prevention of child deaths (Table 1) (8).

There are no available estimates on the effectiveness of appropriate complementary feeding for the prevention of under-five deaths. Further, knowledge is missing on the average coverage of such a feeding pattern during the second half of infancy. Therefore, assessments of the role of complementary feeding in preventing child deaths are based on the assumption that this is mediated through undernutrition and its impact on child mortality (Table 1) (8).

During recent years evidence has been presented that zinc supplements have a role in treatment as well as in the prevention of under-five deaths in zinc-deficient populations. A daily supplement of $10-20 \mathrm{mg}$ zinc during episodes of diarrhoeal diseases and pneumonia reduces the duration of the episode, prevents a new disease episode and also seems to reduce the risk of subsequent death (13, 14). Similarly, preventive supplements of zinc in daily or weekly doses reduce morbidity and probably mortality (15). Zinc supplementation as treatment or prevention has a low coverage, and the potential impact is therefore relatively great. It is estimated that as much as $9 \%$ of current child mortality could be prevented by zinc supplements (Table 1) (8). 


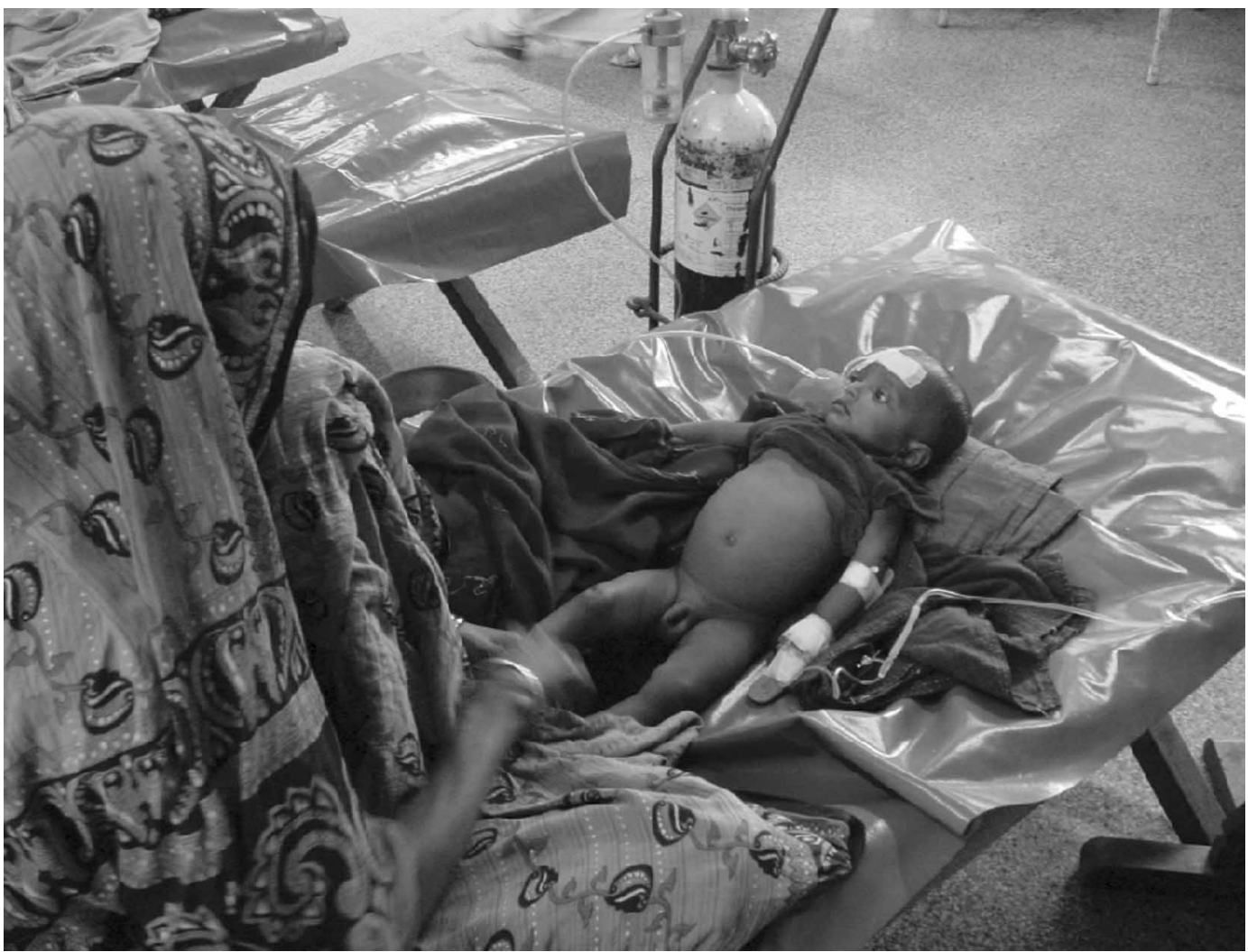

Fig. 1. A 9-month-old child admitted to Matlab Hospital, Bangladesh, with undernutrition, dehydrated by diarrhoea and suffering from severe bronchopneumonia. Undernutrition substantially contributes to increased mortality risks in children under 5 globally, and is an underlying cause of death in more than $50 \%$ of annual child deaths. Breast-feeding, appropriate complementary feeding, zinc supplementation and oral rehydration therapy all play important roles in preventing deaths caused by diarrhoea and pneumonia.

Starting from observations that children with xerophthalmia frequently had higher mortality risks from common infectious diseases than those with

Table I. Efficacious nutrition-related interventions in children under 5 years of age: current estimated coverage of these interventions and potential impact on global child deaths

\begin{tabular}{|c|c|c|}
\hline Intervention & $\begin{array}{l}\text { Current estimated } \\
\text { coverage }(\%)\end{array}$ & $\begin{array}{l}\text { Estimated } \\
\text { proportion of all } \\
\text { under-five deaths } \\
\text { prevented (\%) }\end{array}$ \\
\hline $\begin{array}{l}\text { Exclusive breast-feeding up to } \\
6 \text { months }\end{array}$ & 39 & 13 \\
\hline Breast-feeding 6 - II months & 90 & \\
\hline Complementary feeding & a & $6^{\mathrm{a}}$ \\
\hline Zinc supplementation (preventive) & 0 & 5 \\
\hline Zinc treatment & 0 & 4 \\
\hline Vitamin A supplementation (preventive) & 55 & 2 \\
\hline Vitamin A treatment & 55 & $<1$ \\
\hline Oral rehydration therapy & 20 & 15 \\
\hline
\end{tabular}

Data from Jones et al. (8).

${ }^{a}$ Estimated by using mean weight for age assuming a causal role of appropriate complementary feeding in preventing mortality mediated by underweight. normal vitamin A status, Sommer and colleagues performed a randomized controlled community trial of vitamin A supplementation (capsules containing 200000 IU vitamin A 6-monthly). They demonstrated a reduction in child mortality above 1 year of age of $34 \%$ (16). Later supplementation trials have shown significant reductions in mortality in most (but not all) cases (17). Coverage of vitamin A supplementation is estimated at $55 \%$ of eligible populations worldwide, corresponding to a potential impact on child mortality of $2 \%$ with optimal coverage (8).

ORT is not a conventional nutrition intervention, but is the best therapy given in most cases of diarrhoea and dehydration, together with continued breast-feeding (18). It is estimated that more than 40 million deaths have been prevented by this intervention since the 1970s, and the annual number of under-five deaths caused by diarrhoea has fallen from 4.6 million in 1980 to about 1.5 million in recent years. Still, the mean coverage by this intervention is only $20 \%$, resulting in a potential 
impact on total child mortality in the order of $15 \%$ with universal coverage (8).

\section{Discussion}

Undernutrition is an underlying cause in more than half of global under-five deaths. There is evidence that specific and efficacious nutrition interventions could prevent more than one-third of the current 10 million child deaths. The most important nutritionrelated interventions are exclusive breast-feeding, zinc supplements for treatment and prevention, complementary feeding and vitamin A supplementation. There is a special role for ORT, which could prevent $15 \%$ of child deaths if universally implemented.

Child survival improved dramatically from the 1970 s to the early 1990s, followed by a decelerating trend, especially in sub-Saharan Africa. This is only partly explained by the advance of the HIV/ AIDS pandemic; a major role is the lack of progress in the fight against old and well-known killers such as diarrhoea, pneumonia and diseases of the newborn.

The challenge today, apart from the mobilization of new resources to cover increased costs, is to translate knowledge into action. Progress is monitored regularly as part of the follow-up to the Millennium Development Goals, including monitoring of inequities in child survival within and between countries $(2,4)$. There are several examples of successful strategies for the different nutrition interventions discussed. The role of perinatal and child health services in supporting exclusive breastfeeding is well described, and the efficacy of specific interventions, such as home-based peer counselling, has been documented (19). The knowledge base is relatively weak regarding interventions aiming to improve complementary feeding. There are few if any studies providing data on the effect on child survival of improved infant feeding during the second half of infancy. This lack of basic knowledge is embarrassing, given the importance given to infant feeding for current and later health development. Otherwise, the limitations in current knowledge are related especially to strategies for scalingup, moving from efficacy of interventions to the effectiveness of large-scale implementation of knowledge (20).

The Bellagio Study Group on Child Survival estimated that 6 million out of an annual 10 million child deaths could be prevented by 23 proven interventions (including nutrition interventions) (8). Recently a cost estimate of these interventions was reported, indicating that US \$5.1 billion in new resources is needed annually to save these 6 million child lives. This corresponds to $\$ 1.23$ per head in the 42 countries generating these cases or a mean cost per life saved of $\$ 887$ (21). From an economic point of view investment in child survival and children's health is argued to be a sound economic decision for governments to take, apart from any moral justifications for such programmes (22).

Thus, the Millennium Development Goal on child survival can be reached. The necessary efficacious nutrition interventions already exist, along with other well-established interventions. The cost is affordable for donors and developing countries. The challenge is to prioritize child survival on the global agenda, and to meet the challenge of scaling-up preventive interventions and allocating the necessary new resources.

\section{References}

1. Ahmad OB, Lopez AD, Inoue M. The decline in child mortality: a reappraisal. Bull World Health Organ 2000; 78: 1175-91.

2. United Nations. The Millennium Development Goals Report. New York: United Nations; 2005.

3. Black RE, Morris SS, Bryce J. Where and why are 10 million children dying every year? Lancet 2003; 361: 2226-34.

4. Victora CG, Wagstaff A, Schellenberg JA, Gwatkin D, Claeson M, Habicht J-P. Applying an equity lens to child health and mortality: more of the same is not enough. Lancet 2003; 362: 233-41.

5. Scrimshaw NS, SanGiovanni JP. Synergism of nutrition, infection, and immunity: an overview. Am J Clin Nutr 1998; 66: 464-77.

6. Chandra RK. Nutrition and the immune system from birth to old age. Eur J Clin Nutr 2002; 56 (Suppl 3): S73-6.

7. Murray CJL, Lopez AD. Global mortality, disability, and the contribution of risk factors: Global Burden of Disease Study. Lancet 1997; 349: 1436-42.

8. Jones G, Steketee RW, Black RE, Bhutta ZA, Morris SS, Bellagio Child Survival Study Group. How many child deaths can we prevent this year? Lancet 2003; 362: 6571 .

9. Pelletier DL, Frongillo EA, Habicht J-P. Epidemiologic evidence for a potentiating effect of malnutrition on child mortality. Am J Public Health 1993; 83: 11303.

10. Caulfield LE, de Onis M, Blössner M, Black RE. Undernutrition as an underlying cause of child deaths 
associated with diarrhea, pneumonia, malaria and measles Am J Clin Nutr 2004; 80: 193-8.

11. Habicht JP, WHO Expert Consultation. Expert consultation on the optimal duration of exclusive breastfeeding: the process, recommendations, and challenges for the future. Adv Exp Med Biol 2004; 554: 7987.

12. Bahl R, Frost C, Kirkwood BR, Edmond K, Martines J, Bhandari N, Arthur P. Infant feeding patterns and risks of death and hospitalization in the first half of infancy: multicentre cohort study. Bull World Health Organ 2005; 83: 418-26.

13. Bhutta ZA, Bird SM, Black RE, Brown KH, Gardner JM, Hidayat A, et al. Therapeutic effects of oral zinc in acute and persistent diarrhea in children in developing countries: pooled analysis of randomized controlled trials. Am J Clin Nutr 2000; 72: 1516-22.

14. Baqui AH, Black RE, Arifeen SE, Yunus M, Chakraborty J, Ahmed S, Vaughan JP. Effect of zinc supplementation started during diarrhoea on morbidity and mortality in Bangladeshi children: community randomised trial. BMJ 2002; 325: 1059-64.

15. Brooks WA, Santosham M, Naheed A, Wahed MA, Diener-West M, Faruque ASG, Black RE. Effect of weekly zinc supplements on incidence of pneumonia and diarrhoea in children younger than 2 years in an urban, low-income population in Bangladesh: randomised controlled trial. Lancet 2005; 366: 9991004.

16. Sommer A, Djunaedi E, loeden AA, Tarwoto I, West KP, Tilden R. Impact of vitamin A supplementation on childhood mortality. A randomized controlled community trial. Lancet 1986; i: 1169-73.

17. Villamor E, Fawzi WW. Vitamin A supplementation: implications for morbidity and mortality in children. $\mathbf{J}$ Infect Dis 2000; 182 (Suppl 1): S122-33.

18. Victora CG, Bryce J, Fontaine O, Monasch R. Reducing deaths from diarrhoea through oral rehydration therapy. Bull World Health Organ 2000; 78: 1246-55.

19. Morrow AL, Guerrero ML, Shults J, Calva JJ, Lutter C, Bravo J, et al. Efficacy of home-based peer counseling to promote exclusive breastfeeding: a randomized controlled trial. Lancet 1999; 353: 1226-31.

20. Bellagio Study Group on Child Survival. Knowledge into action for child survival. Lancet 2003; 362: 323-7.

21. Bryce J, Black RE, Walker N, Bhutta ZA, Steketee RW. Can the world afford to save the lives of 6 million children each year? Lancet 2005; 365: 2193-200.

22. Belli PC, Bustreo F, Preker A. Investing in children's health: what are the economic benefits? Bull World Health Organ 2005; 83: 777-84.

\author{
Lars Åke Persson \\ International Maternal and Child Health \\ Department of Women's and Children's Health \\ Uppsala University \\ SE-75I 85 Uppsala, Sweden \\ Tel: +46 18 6119294 \\ Fax: +4618508013 \\ E-mail: lars-ake.persson@kbh.uu.se
}

